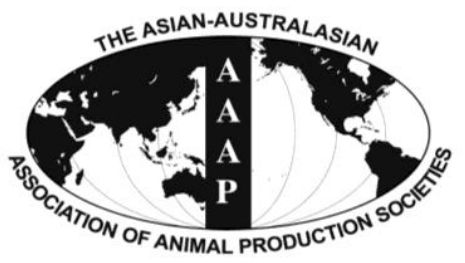

\title{
Molecular Characterization and Expression Pattern of Gene IGFBP-5 in the Cashmere Goat (Capra hircus)
}

\author{
X. J. Wang ${ }^{1, \text { a }}$, J. J. Shi ${ }^{1,2, a}$, J. F. Yang ${ }^{1}$, Y. Liang ${ }^{1}$, Y. F. Wang ${ }^{1}$, M. L. Wu ${ }^{1}$, \\ S. Y. Li ${ }^{1}$, X. D. Guo ${ }^{1}$, Z. G. Wang ${ }^{1} *$ and D. J. Liu ${ }^{1}$ \\ ${ }^{1}$ College of Life Science, Inner Mongolia University, \\ The Key Laboratory of Mammal Reproductive Biology and Biotechnology, \\ Ministry of Education, Hohhot 010021, China
}

\begin{abstract}
Insulin-like growth factor-binding protein-5 (IGFBP-5) is one of the six members of IGFBP family, important for cell growth, apoptosis and other IGF-stimulated signaling pathways. In order to explore the significance of IGFBP-5 in cells of the Inner Mongolian Cashmere goat (Capra hircus), IGFBP-5 gene complementary DNA (cDNA) was amplified by reverse transcription polymerase chain reaction (RT-PCR) from the animal's fetal fibroblasts and tissue-specific expression analysis was performed by semiquantitative RT-PCR. The gene is 816 base pairs (bp) in length and includes the complete open reading frame, encoding 271 amino acids (GenBank accession number JF720883). The full cDNA nucleotide sequence has a 99\% identity with sheep, 98\% with cattle and 95\% with human. The amino acids sequence shares identity with $99 \%, 99 \%$ and $99 \%$, respectively. The bioinformatics analysis showed that IGFBP-5 has an insulin growth factor-binding protein homologues (IB) domain and a thyroglobulin type-1 (TY) domain, four protein kinase $\mathrm{C}$ phosphorylation sites, five casein kinase II phosphorylation sites, three prenyl group binding sites (CaaX box). The IGFBP-5 gene was expressed in all the tested tissues including testis, brain, liver, lung, mammary gland, spleen, and kidney, suggesting that $I G F B P-5$ plays an important role in goat cells. (Key Words: Cashmere Goat, IGFBP-5, Expression Pattern, Tissue-specific, Hair, Gene)
\end{abstract}

\section{INTRODUCTION}

Insulin-like growth factor-binding proteins (IGFBPs) are a family of secreted proteins that bind insulin-like growth factors I and II (IGFs I and II). IGFBPs are capable of modulating IGF actions on target cells (James et al., 1993). Insulin-like growth factor-binding protein-5 (IGFBP5 ) is a critical member of IGFBP family (Beattie et al., 2006) and it is the most evolutionarily conserved member of the IGFBP family (Allander et al., 1994). IGFBP-5 plays an important role in several biological processes including bone, ovary, mammary gland and kidney physiology (Kelley et al., 1996). The function of IGFBP-5 is mainly emphasized on cell growth and the protein either suppresses or induces cell proliferation (Andress and Birnbaum, 1992;

\footnotetext{
* Corresponding Author: Z. G. Wang. Tel: +86-471-49958678008, Fax: +86-471-4992435, E-mail: lswzg@imu.edu.cn

${ }^{2}$ School of life Sciences and Technology, Tongji University, Siping Road, Yangpu District, Shanghai 200092, China.

a These authors contributed equally to this work. Submitted Aug. 19, 2011; Accepted Oct. 25, 2011; Revised Dec. 1, 2011
}

Ewton et al., 1998; Meadows et al., 2000; Schneider et al., 2001). In addition, it interacts with several extracellular matrix proteins including thrombospondin-1 (Nam et al., 2002), osteopontin (Nam et al., 2002), vitronectin (Nam et al., 2000) and plasminogen activator inhibitor-1 (Nam et al., 1997). In the past few years, it has been shown that the effect of IGFBP-5 on cell survival seems to be based on interactions with specific soluble or cell-associated ligands (Beattie et al., 2006; Hung et al., 2008; Schneider et al., 2002).

Until recently, the mechanisms controlling the development and differentiation of hair remained unexplored. However, studies have demonstrated that IGFBP-5 is associated with hair differentiation. During embryogenesis and early postnatal development, four different hair types were designated guard, awl, zigzag and auchene hair (Dry, 1926). Segmental IGFBP-5 expression is specifically associated with the bent structure of zigzag hair and can be identified as a central regulator of hair shaft differentiation and hair type determination (Schlake, 2005b). Otherwise, IGFBP-5-mediated FGFR2-IIIb signals 
represent a key regulator of the genetic program that controls the structure of the hair shaft medulla (Schlake, 2005a). IGFBP-5 has been seen as a key molecule in formation of the bent hair structure of zigzag hair. Sriwiriyanont et al. (2011) reported that twisted hair shafts as well as an unusual deposition of hair cuticle resulted from overexpression of IGFBP-5 in human hair xenografts, the mechanism for which is the disturbance of normal proliferation and differentiation (Sriwiriyanont et al., 2011). IGFBP-5 has an effect on human hair shape, and that lentiviral transduction regimen can be used for functional analysis of genes involved in human hair morphogenesis (Sriwiriyanont et al., 2011).

Progress has been made in the identification of the IGFBP-5 gene in humans, mice and rats, but little is known about the role of the gene in small ruminants. Specifically, we have little knowledge of the role of IGFBP-5 in goat cells. In the present study, we cloned the code sequence fragment of the IGFBP-5 gene cDNA from the Inner Mongolia Cashmere Goat (Capra hircus) and used basic bioinformatics to analyze this gene and its gene product in order to study the molecular characterization. To study the expression pattern of the IGFBP-5 gene, semi-quantitative reverse transcription polymerase chain reaction (RT-PCR) was used to detect the relative expression levels in various tissues of the Inner Mongolia Cashmere goat. Furthermore, a eukaryotic expression vector of the goat IGFBP-5 gene was constructed and then transferred into Inner Mongolia Cashmere goat fetal fibroblasts to obtain a transgenic cell clones. The transgenic cells will be used to produce an increased cashmere production from transgenic goats and to produce a new variety of genetically modified cashmere goats.

\section{MATERIALS AND METHODS}

\section{Animal and tissue samples}

The Inner Mongolia Cashmere goat aged $1.5 \mathrm{yr}$ used in this study was bred on a natural diet in Inner Mongolia, China. Tissues including testis, brain, liver, lung, mammary gland, spleen, and kidney were collected from the goat after slaughter in a commercial goat slaughter farm in the spring. Tissue samples were immediately frozen in liquid nitrogen and stored at $-80^{\circ} \mathrm{C}$.

\section{Cell culture conditions}

Inner Mongolia Cashmere goat fetal fibroblasts $(\mathrm{GFb}$ cells) were maintained as monolayer cultures in DMEM/F12 (D-MEM/F-12, Gibco, Paisley, PA49RF, Scotland, UK) supplemented with $10 \%$ fetal bovine serum (FBS) and 100 $\mathrm{U} / \mathrm{ml}$ penicillin $\mathrm{G}$ and $100 \mathrm{mg} / \mathrm{ml}$ streptomycin (FBS, Hyclone Laboratories, Inc. Logan, UT USA and penicillin/streptomycin, Sigma-Aldrich, Inc. St. Louis USA). Cell cultures were maintained and incubated at $37^{\circ} \mathrm{C}$ in humidified air with $5 \% \mathrm{CO}_{2}$.

\section{Total ribonucleic acid (RNA) extraction and 1st strand cDNA synthesis}

Total RNA was isolated from Inner Mongolia goat fetal fibroblasts, using an RNAzol (RNAiso Plus, Takara Co. Ltd, Dalian, China). RNA concentration was determined spectrophotometrically. RNA was reversely transcribed with an AMV 1st strand cDNA Synthesis kit, and an oligo d $(\mathrm{T})_{18}$ primer was used according to manufacturer's protocol (Takara Co. Ltd, Dalian, China). An input of $1 \mu \mathrm{g}$ total RNA was used for the reaction.

\section{Cloning and sequencing of IGFBP-5 gene cDNA}

To amplify the Inner Mongolia Cashmere goat IGFBP-5 gene cDNA fragments, a pair of specific primers was designed based on the Ovis aries IGFBP-5 sequence (EU727460). The forward primer (fw): 5'-GCGAATTCGT CGACATGGTGCTCACCGCGSTC-3' (S means G or C), containing EcoRI and SalI restriction sites at $5^{\prime}$ site. The reverse primer (rv): 5'-CGGCATGCCGCATCACTCAA CRTTRCTGCTG-3' (R means A or G), containing SphI restriction sites in the $5^{\prime}$ site. $\mathrm{PCR}$ was conducted at $94^{\circ} \mathrm{C}$ for $4 \mathrm{~min}$; followed by 35 cycles of $94^{\circ} \mathrm{C}$ for $30 \mathrm{~s}$ at $58^{\circ} \mathrm{C}$ for $1 \mathrm{~min}$, and $72^{\circ} \mathrm{C}$ for $1 \mathrm{~min} ; 72^{\circ} \mathrm{C}$ for $10 \mathrm{~min}$. PCR reaction mixture $(10 \mu \mathrm{l})$ containing TaKaRa LA Taq (TaKaRa Taq Version, Takara Co. Ltd., Dalian, China) 0.1 $\mu l, 2 \times$ GC Buffer I (TaKaRa Taq Version, Takara Co. Ltd., Dalian, China) $5 \mu \mathrm{l}$, dNTP Mixture (2.5 mm each) $1.6 \mu \mathrm{l}$, template cDNA $1.0 \mu \mathrm{l}$, fw primer $(10 \mu \mathrm{m})$ and rv primer $(10$ $\mu \mathrm{m})$ mixture $0.8 \mu \mathrm{l}, \mathrm{d}_{3} \mathrm{H}_{2} \mathrm{O} 1.5 \mu \mathrm{l}$. PCR products were then electrophoresed and photographs were taken by an electronic UV transilluminator (UVItec, London, UK). The PCR products were purified and cloned into pMD19-T vector (Takara Co. Ltd, Dalian, China) followed by sequencing. The predicted length was $816 \mathrm{bp}$.

\section{Tissue distribution of Cashmere goat IGFBP-5 mRNA}

Tissue distribution of IGFBP-5 messenger RNA (mRNA) was performed using semi-quantitative RT-PCR analysis. Total RNA from testis, brain, liver, lung, mammary gland, spleen, and kidney was extracted and reverse-transcribed. The PCR amplifications were performed in $10 \mu \mathrm{l}$ total volume for 35 cycles at the appropriate annealing temperature with the primers similar to that of the coding sequence (CDS) fragment. IGFBP-5 mRNA was detected in different tissues with $\beta$-actin as a loading control. PCR amplification of $\beta$-actin gene was performed for 30 cycles at the appropriate annealing 


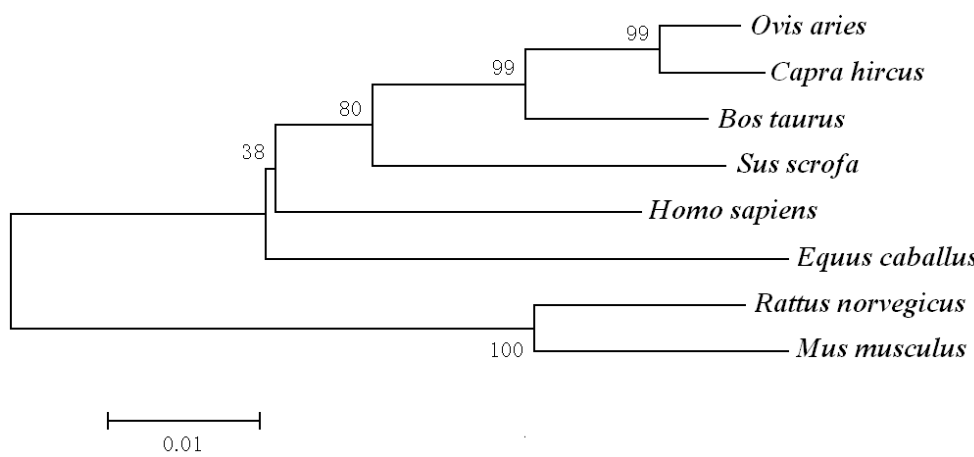

Figure 1. Phylogenetic tree for $I G F B P-5$ genes in seven species. The cloned goat $I G F B P-5$ gene nucleotide sequence was aligned with other homologous animal IGFBP-5 genes. The phylogenetic tree was constructed by the neighbor-joining method using MEGA 4.1 software. The species and GenBank accession numbers are Ovis aries (EU727460), Capra hircus (JF720883), Bos taurus (NM_001105327), Sus scrofa (SSU41340), Homo sapiens (NM_000599), Equus caballus (XM_001490309), Rattus norvegicus (NM_012817) and Mus musculus (BC057447). The genetic relationship between goat and sheep is very close.

temperature with the following pairs of primers, forward: $5^{\prime}$ -TGGCACCACACCTTCTACAACGAGC-3', reverse: 5'CGTCCCCAGAGTCCATGACAATG- $3^{\prime}$. The predicted fragment was $229 \mathrm{bp}$.

\section{Bioinformatics analysis}

Nucleotide sequence of Cashmere goat IGFBP-5 cDNA and deduced amino acid sequence were identified by the National Center for Biotechnology Information (NCBI) Basic Local Alignment Search Tool (BLAST) program (http://www.ncbi.nlm.nih.gov/BLAST/). Open reading frames (ORFs) and theoretical molecular weight of deduced polypeptides were predicted by the Protein property calculator (http://www.basic.northwestern.edu/biotools/ proteincalc.html). The protein isoelectric point was predicted using the calculation of protein isoelectric point (http://isoelectric.ovh.org/). Protein domain analysis was identified by the Simple Modular Archtitecture Research Tool (SMART) program (http://smart.embl-heidelberg.de/). Protein prosite patterns were identified by the Psite program (http://www.softberry.com). A phylogenetic tree was constructed by using the MEGA 4.1 program.

\section{RESULTS}

cDNA cloning and sequence analysis of IGFBP-5 gene cDNA

The IGFBP-5 gene cDNA (GenBank accession number JF720883) from the Inner Mongolia Cashmere goat was amplified by RT-PCR. The cloned cDNA fragment was 816 bp in length and included completed ORF encodingdeduced 271 amino acid residues. The full cDNA nucleotide sequence showed a 99\%, 98\%, and 95\% identity with sheep, cattle, and humans, respectively. The amino acid sequence shares identity with $99 \%, 99 \%$ and $99 \%$ of those groups, respectively. To elucidate the phylogenetic relationships of the IGFBP-5 gene, their nucleotide sequences were aligned with other homologous animal IGFBP-5 gene sequences and a phylogenetic tree was constructed as shown in Figure 1. As a result, we can infer that the genetic relationship between goat and sheep is close.

Primary structure and secondary structure of the Cashmere goat IGFBP-5 protein

The deduced IGFBP-5 protein of the Inner Mongolia Cashmere goat consists of 271 amino acid residues and its predicted molecular weight is $30.42 \mathrm{kDa}$ for the unmodified protein and the estimated isoelectric point (pI) is 8.32. IGFBP-5 has $18.8 \%$ acidic amino acids and $26.2 \%$ basic amino acids. The basic amino acids comprise $7.75 \%$ lysine, 8.49\% arginine, $2.95 \%$ histidine and $7.01 \%$ proline. IGFBP-5 has a low complexity amino acid starting at 3 and extending to 21, an IB domain at positions 24 - 101, which is made up of amino acids Val68, Tyr69, Pro81 and Lys87Leu94. Amino acids 215 to 266 form a thyroglobulin type-1 (TY) domain (Figure 2). The $\mathrm{N}$ terminus is the primary binding site for IGFs. There is one cAMP- and cGMPdependent protein kinase phosphorylation site, four protein kinase C phosphorylation sites, five casein kinase II phosphorylation sites, three prenyl group binding sites (CaaX box), three microbody C-terminal targeting signals and one thyroglobulin type-1 repeat signature. The protein prosite compared with IGFBP-5 in other animals was constructed as shown in Figure 3

\section{Tissue distribution of the Cashmere goat IGFBP-5 mRNA}

To determine the steady-state level expression of the IGFBP-5 gene in different goat tissues, semi-quantitative RT-PCR analysis was carried out with total RNA extracted from testis, brain, liver, lung, mammary gland, spleen, and kidney (Figure 4). The IGFBP-5 gene was expressed in all 


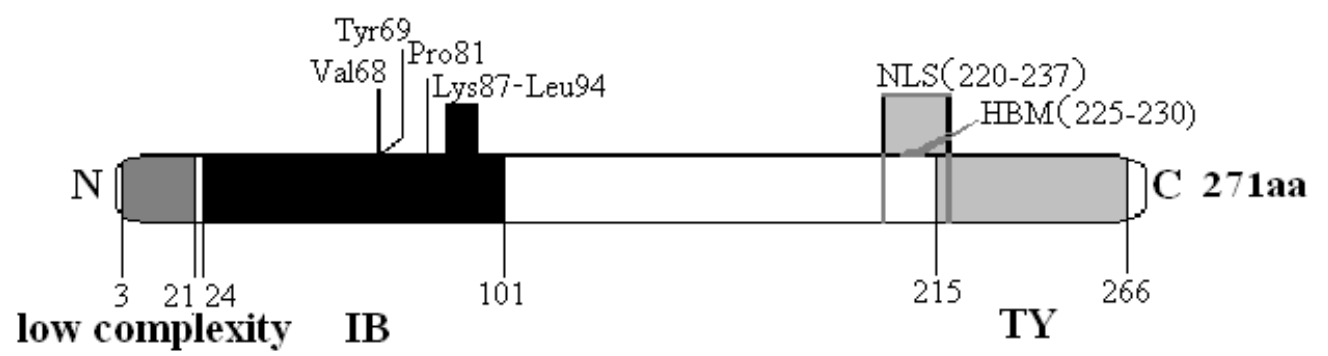

Figure 2. The predicted domain of goat IGFBP-5 protein. IGFBP-5 has a low complexity amino acid starting at 3 to 21 . There are two main domains in the IGFBP-5 including an IB domain at amino acid position 24-101 and a TY domain at position 215-266. The domains were predicted using SMART Software (http://smart.embl.de/). The primary binding site for IGF in the N terminus of IGFBP-5 has been mapped to ten clustered residues, Va168, Tyr69, Pro81, Lys87-Leu94, and form a hydrophobic patch on the surface of the protein. The amino acids in 220-237 form the NLS, containing an HBM at amino acid 225 to 230.

the tested tissues and the highest level of mRNA accumulation was detected in the kidney.

\section{DISCUSSION}

The IGFBP-5 gene is $17 \mathrm{~kb}$ and has been localized on chromosome 1 in the mouse (Kou et al., 1994). In humans it has a length of $33 \mathrm{~kb}$ and has been localized on chromosome 2 (Allander et al., 1994). IGFBP-5 has a highly cysteine-rich $\mathrm{N}$-terminal domain (twelve cysteine residues) and a cysteine-rich $\mathrm{C}$-terminal domain (six cysteine residues) (Duan, 2002). The $\mathrm{N}$ - and C-domains are highly conserved among various members of the IGFBP family in any given species (Duan, 2002). The N-terminal domain of IGFBP-5 contains the IGF-1 binding region and caveolin binding sites (Ravid et al., 2008). The C-terminal domain cannot bind IGF-1, but it can affect the IGF-1 binding affinity (Shand et al., 2003). A highly basic domain in the C-terminal end of IGFBP-5 (AA220-237) has a functional nuclear localization sequence (Schedlich et al., 1998).

In the deduced goat IGFBP-5 amino acid sequence, the C-terminal domain of IGFBP-5 contains a region known as the nuclear localization sequence (NLS) and this sequence is to be found between amino acids 201 to 218 in humans (Schedlich et al., 1998; Schedlich et al., 2000), but it is located from amino acid 220 to 237 in the goat (Figure 2). The NLS contains a heparin-binding motif (HBM, consensus sequence $\mathrm{BBBXXB}$, where $\mathrm{B}$ is a basic amino acid and $X$ is any amino acid) at amino acid positions 206 to 211 and carries alternative IGF-binding sites in human (Abrass et al., 1997; Allan et al., 2006), but it is at positions 225 to 230 in the goat (Figure 2). The thyroglobulin type-1 (TY) domain is between amino acid 215 to 266, but repeat TY signature is from 214 to 247 amino acids (Figures 2 and 3). Thyroglobulin ( $\mathrm{Tg}$ ) is a large glycoprotein specific to the thyroid gland and is the precursor of the iodinated thyroid hormones thyroxine (T4) and triiodothyronine (T3). This

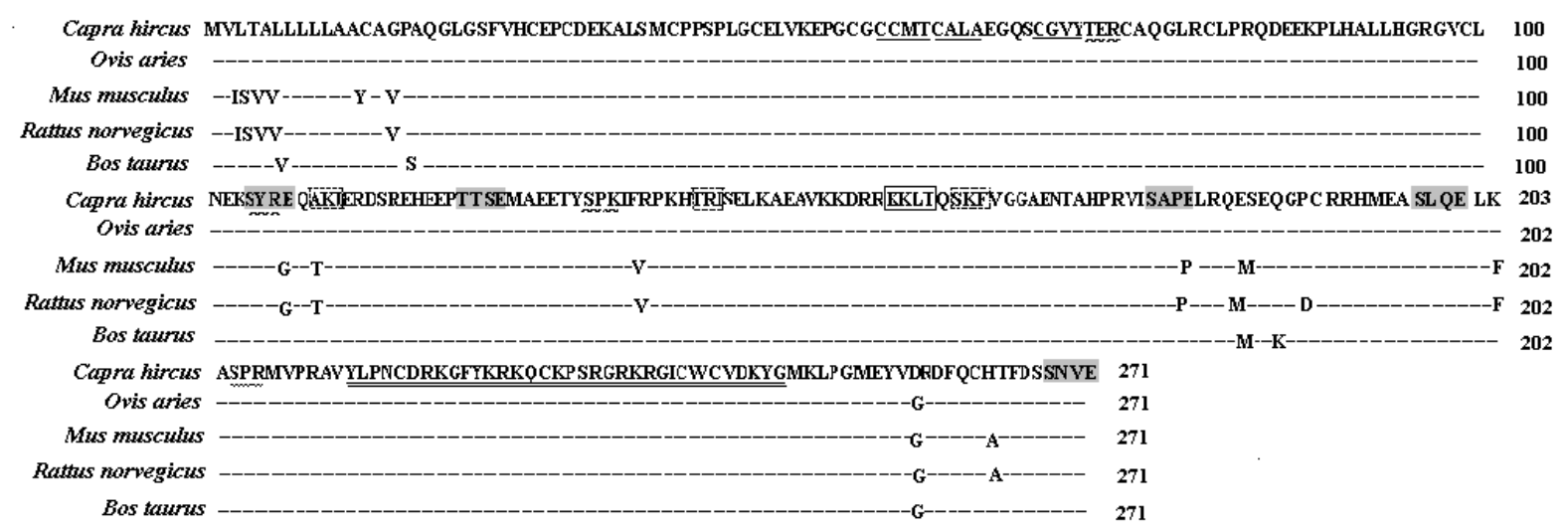

Figure 3. Predicted P sites of IGFBP-5. Alignment of the amino acids sequences of Capra hircus (JF720883), Ovis aries (EU727460), Mus musculus (BC057447), Rattus norvegicus (NM_012817) and Bos taurus (NM_001105327). cAMP-and cGMP-dependent protein kinase phosphorylation sites are marked by a box. Protein kinase $\mathrm{C}$ phosphorylation sites are marked by a wavy line. Casein kinase II phosphorylation sites are marked by a gray box. Prenyl group binding sites (CaaX box) are marked by underlining. Thyroglobulin type-1 repeat signature is marked by double underlines. Microbody C-terminal targeting signals are marked by a hidden line frame. All these were determined using the Psite program (http://www.softberry.com). 
(A)

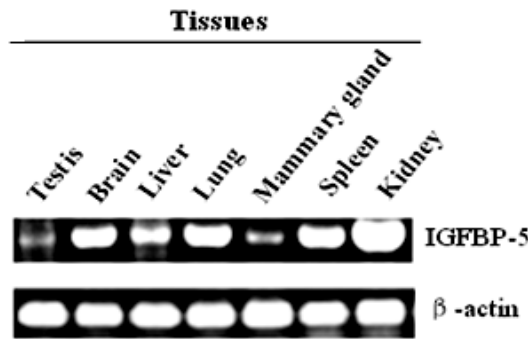

(B)

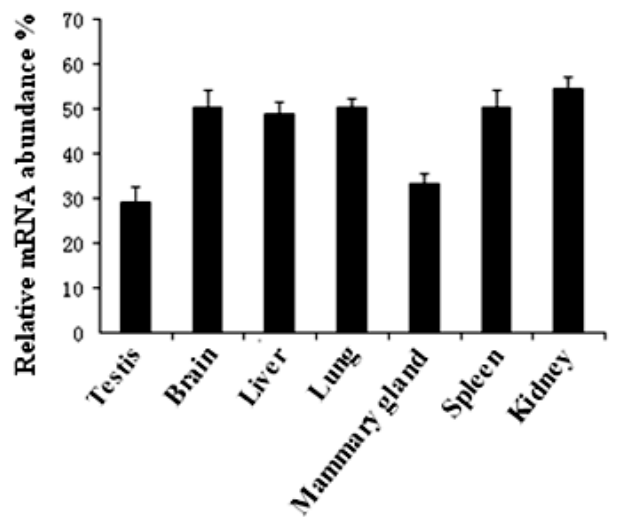

Figure 4. Expression of IGFBP-5 gene in different tissues. (A) Semi-quantitative RT-PCR detection of IGFBP-5 transcripts with $\beta$-actin mRNA as a loading control. (B) The band using gel was analyzed by BandScan software version 5.0.

protein was found to be a potent inhibitor of cysteine proteases (Molina et al., 1996). The $\mathrm{N}$-domain activates transcription independent of IGF (Xu et al., 2004). In the $\mathrm{N}$-domain, some amino acids, comprised of Val49, Tyr50, Pro62 and Lys68-Leu75, form a hydrophobic patch on the surface of the protein in humans (Kalus et al., 1998), but in goats these amino acids are comprised of Val68, Tyr69, Pro81 and Lys87-Leu94. Not only are several basic residues in the IGFBP-5 C-domain necessary and sufficient for nuclear localization of the intact protein, but IGFBP-5 is also present in the nucleus and may affect gene expression independent of the IGF ligand (Zhao et al., 2006). There are ten phosphorylation sites in goats (Figure 3). Graham et al. demonstrated that IGFBP-5 is secreted as a phosphoprotein and O-linked glycoprotein and that there are two main in vivo phosphorylation sites in human IGFBP-5 at Ser96 and Ser248 (Graham et al., 2007). The authors also determined that the majority of secreted IGFBP-5 was phosphorylated (56\%) (Graham et al., 2007). All features indicated are very similar to those found in previous research on IGFBP-5 in other species. These findings indicate that the IGFBP-5 gene has been correctly cloned from the Inner Mongolia Cashmere Goat.

Hair features are affected by many factors, but two major factors are the follicle's capacity and hair growth cycle. It has been demonstrated that IGF-I signalling is an important mitogenic and morphogenetic regulator in hair follicle biology (Weger and Schlake, 2005). IGFBP-5 has been identified as the first molecular marker expressed in zigzag hair follicles (Schlake, 2005b). Some data show that IGFBP-5 regulates hair shaft structure and follicle identity (Schlake, 2005b). In 2006, Schlake cited Krox-20 as a molecular marker whose expression in the proximal follicle appears to be restricted to zigzag hair follicles, and Krox-20 as a nodal point of fibroblast growth factor and IGF signalling pathways controlling IGFBP-5 expression which is associated with hair shaft differentiation and may generate the periodicity of the zigzag hair (Schlake, 2006).

The results of semi-quantitative RT-PCR in adult goat tissues has indicated that IGFBP-5 gene is expressed in various tissues and its expression is enriched in the kidney but restricted to the lung, heart, stomach, adrenal and testis tissues in the rat (Shimasaki et al., 1991). In human pancreatic samples, the IGFBP-5 gene was expressed at higher levels than in normal tissues (Johnson and Haun, 2009). In our study, goat IGFBP-5 mRNA was expressed at the highest level in the kidney and strongly expressed in the brain, liver, lung and spleen while its expression was restricted in the testis and mammary gland. These results suggest that IGFBP-5 played a more important role in highexpression-level tissues than in the testis and mammary gland, so its function in the goat may be different from that in the rat and in humans.

\section{CONCLUSIONS}

In conclusion, our data show that IGFBP-5 cDNA was cloned from the Inner Mongolia Cashmere goat. It is $816 \mathrm{bp}$ in length, including a complete ORF corresponding to a polypeptide of 271 amino acids. The IGFBP-5 gene is expressed in all the tested tissues and the highest level of mRNA accumulation is detected in kidney tissue.

\section{ACKNOWLEDGEMENTS}

This work supported by grant from Natural Sciences Foundation (30860191), graduate student research projects of Inner Mongolia University and Major Projects for New Varieties of Genetically Modified Organisms (2008ZX08008-002), China.

\section{REFERENCES}

Abrass, C. K., A. K. Berfield and D. L. Andress. 1997. Heparin binding domain of insulin-like growth factor binding protein-5 stimulates mesangial cell migration. Am. J. Physiol. 273: F899-906.

Allan, G. J., E. Tonner, M. Szymanowska, J. H. Shand, S. M. Kelly, K. Phillips, R. A. Clegg, I. F. Gow, J. Beattie and D. J. Flint. 2006. Cumulative mutagenesis of the basic residues in the 201- 
218 region of insulin-like growth factor (IGF)-binding protein5 results in progressive loss of both IGF-I binding and inhibition of IGF-I biological action. Endocrinology 147:338349.

Allander, S. V., C. Larsson, E. Ehrenborg, A. Suwanichkul, G. Weber, S. L. Morris, S. Bajalica, M. C. Kiefer, H. Luthman and D. R. Powell. 1994. Characterization of the chromosomal gene and promoter for human insulin-like growth factor binding protein-5. J. Biol. Chem. 269:10891-10898.

Andress, D. L. and R. S. Birnbaum. 1992. Human osteoblastderived insulin-like growth factor (IGF) binding protein-5 stimulates osteoblast mitogenesis and potentiates IGF action. J. Biol. Chem. 267:22467-22472.

Beattie, J., G. J.Allan, J. D. Lochrie and D. J. Flint. 2006. Insulinlike growth factor-binding protein-5 (IGFBP-5): a critical member of the IGF axis. Biochem. J. 395:1-19.

Dry, F. 1926. The coat of the mouse (Mus musculus). J. Genet. 16: 287-340.

Duan, C. 2002. Specifying the cellular responses to IGF signals: roles of IGF-binding proteins. J. Endocrinol. 175:41-54.

Ewton, D. Z., S. A. Coolican, S. Mohan, S. D. Chernausek and J. R. Florini. 1998. Modulation of insulin-like growth factor actions in L6A1 myoblasts by insulin-like growth factor binding protein (IGFBP)-4 and IGFBP-5: a dual role for IGFBP-5. J. Cell. Physiol. 177:47-57.

Graham, M. E., D. M. Kilby, S. M. Firth, P. J. Robinson and R. C. Baxter. 2007. The in vivo phosphorylation and glycosylation of human insulin-like growth factor-binding protein-5. Mol. Cell. Proteomics 6:1392-1405.

Hung, P. S., S. Y. Kao, Y. H. Shih, S. H. Chiou, C. J. Liu, K. W. Chang and S. C. Lin. 2008. Insulin-like growth factor binding protein-5 (IGFBP-5) suppresses the tumourigenesis of head and neck squamous cell carcinoma. J. Pathol. 214:368-376.

James, P. L., S. Jones, W. Busby, D. Clemmons and P. Rotwein. 1993. A highly conserved insulin-like growth factor-binding protein (IGFBP-5) is expressed during myoblast differentiation. J. Biol. Chem. 268:22305-22312.

Johnson, S. K. and R. S.Haun. 2009. Insulin-like growth factor binding protein-5 influences pancreatic cancer cell growth. World J. Gastroenterol. 15:3355-3366.

Kalus, W., M. Zweckstetter, C. Renner, Y. Sanchez, J. Georgescu, M. Grol, D. Demuth, R. Schumacher, C. Dony and K. Lang. 1998. Structure of the IGF-binding domain of the insulin-like growth factor-binding protein-5 (IGFBP-5): implications for IGF and IGF-I receptor interactions. EMBO. J. 17:6558-6572.

Kelley, K. M., Y. Oh, S. E. Gargosky, Z. Gucev, T. Matsumoto, V. Hwa, L. Ng, D. M. Simpson and R. G. Rosenfeld. 1996. Insulin-like growth factor-binding proteins (IGFBPs) and their regulatory dynamics. Int. J. Biochem. Cell Biol. 28:619-637.

Kou, K., P. L. James, D. R. Clemmons, N. G. Copeland, D. J. Gilbert, N. A. Jenkins and P. Rotwein. 1994. Identification of two clusters of mouse insulin-like growth factor binding protein genes on chromosomes 1 and 11. Genomics 21:653655.

Meadows, K. A., J. M. P. Holly and C. E. H. Stewart. 2000. Tumor necrosis factor- $\alpha$-induced apoptosis is associated with suppression of insulin-like growth factor binding protein-5 secretion in differentiating murine skeletal myoblasts. J. Cell.
Physiol. 183: 330-337.

Molina, F., M. Bouanani, B. Pau and C. Granier. 1996. Characterization of the Type-1 repeat from thyroglobulin, a cysteine-rich module found in proteins from different families. Eur. J. Biochem. 240:125-133.

Nam, T., A. Moralez and D. Clemmons. 2002. Vitronectin binding to IGF binding protein-5 (IGFBP-5) alters IGFBP-5 modulation of IGF-I actions. Endocrinology 143:30-36.

Nam, T. J., W. Busby, Jr. and D. R.Clemmons. 1997. Insulin-like growth factor binding protein-5 binds to plasminogen activator inhibitor-I. Endocrinology 138:972-2978.

Nam, T. J., W. H. Busby, Jr., C. Rees and D. R. Clemmons. 2000. Thrombospondin and osteopontin bind to insulin-like growth factor (IGF)-binding protein-5 leading to an alteration in IGFI-stimulated cell growth. Endocrinology 141:1100-1106.

Ravid, D., D. Chuderland, L. Landsman, Y. Lavie, R. Reich and M. Liscovitch. 2008. Filamin A is a novel caveolin-1-dependent target in IGF-I-stimulated cancer cell migration. Exp. Cell Res. 314:2762-2773.

Schedlich, L. J., S. L. Le Page, S. M. Firth, L. J. Briggs, D. A. Jans and Baxter R. C. 2000. Nuclear import of insulin-like growth factor-binding protein- 3 and -5 is mediated by the importin $\beta$ subunit. J. Biol. Chem. 275:23462-23470.

Schedlich, L. J., T. F. Young, S. M. Firth and R. C. Baxter. 1998. Insulin-like growth factor-binding protein (IGFBP)-3 and IGFBP5 share a common nuclear transport pathway in T47D human breast carcinoma cells. J. Biol. Chem. 237:1834718352.

Schlake, T. 2005a. FGF signals specifically regulate the structure of hair shaft medulla via IGF-binding protein 5. Development 132:2981-2990.

Schlake, T. 2005b. Segmental Igfbp5 expression is specifically associated with the bent structure of zigzag hairs. Mech. Dev. 122:988-997.

Schlake, T. 2006. Krox20, a novel candidate for the regulatory hierarchy that controls hair shaft bending. Mech. Dev. 123: 641-648.

Schneider, M., E. Wolf, A. Hoeflich and H. Lahm. 2002. IGFbinding protein-5: flexible player in the IGF system and effector on its own. J. Endocrinol. 172:423-440.

Schneider, M. R., R. Zhou, A. Hoeflich, O. Krebs, J. Schmidt, S. Mohan, E. Wolf and H. Lahm. 2001. Insulin-like growth factor-binding protein-5 inhibits growth and induces differentiation of mouse osteosarcoma cells. Biochem. Biophys. Res. Commun. 288:435-442.

Shand, J. H., J. Beattie, H. Song, K. Phillips, S. M. Kelly, D. J. Flint and G. J. Allan. 2003. Specific amino acid substitutions determine the differential contribution of the $\mathrm{N}$ - and Cterminal domains of insulin-like growth factor (IGF)-binding protein-5 in binding IGF-I. J. Biol. Chem. 278:17859-17866.

Shimasaki, S., M. Shimonaka, H. P. Zhang and N. Ling. 1991. Identification of five different insulin-like growth factor binding proteins (IGFBPs) from adult rat serum and molecular cloning of a novel IGFBP-5 in rat and human. J. Biol. Chem. 266:10646-10653.

Sriwiriyanont, P., A. Hachiya, W. L. Pickens, S. Moriwaki, T. Kitahara, M. O. Visscher, W. J. Kitzmiller, A. Bello, Y. Takema and G. P. Kobinger. 2011. Effects of IGF-binding protein 5 in 
dysregulating the shape of human hair. J. Invest. Dermatol. Xu, Q., S. Li, Y. Zhao, T. J. Maures, P. Yin and C. Duan. 2004. 131:320-328.

Weger, N. and T. Schlake. 2005. Igf-I signalling controls the hair growth cycle and the differentiation of hair shafts. J. Invest. Dermatol. 125:873-882. Evidence that IGF binding protein-5 functions as a ligandindependent transcriptional regulator in vascular smooth muscle cells. Circ. Res. 94:E46-54.

Zhao, Y., P. Yin, L. A. Bach and C. Duan. 2006. Several acidic amino acids in the $\mathrm{N}$-domain of insulin-like growth factorbinding protein-5 are important for its transactivation activity. J. Biol. Chem. 281:14184-14191. 